\title{
GIS DATA COLLECTION FOR PEDESTRIAN FACILITIES AND FURNITURE USING MAPINR FOR ANDROID
}

\author{
N. Naharudin ${ }^{\mathrm{a}}{ }^{*}$, M. S. S. Ahamad ${ }^{\text {a }}$, A. F. M. Sadullah ${ }^{\mathrm{a}}$ \\ School of Civil Engineering, Engineering Campus, Universiti Sains Malaysia, 14300 Nibong Tebal, Penang \\ -nn15_civ014@student.usm.my, cesanusi@usm.my, cefrhn@usm.my
}

KEY WORDS: GIS, spatial data collection, Mobile GIS, smartphones, android, MAPInr

\begin{abstract}
:
Mobile GIS is introduced to reduce the time taken in completing the field data collection procedure. With the expansion of technology today, mobile GIS is not far behind. It can be integrated with the high-end innovation tools like smartphones. Spatial data capture which deemed to be the toughest stage of a GIS project is made simple with this method. Many studies had demonstrated the usage of mobile GIS in collecting spatial data and this paper discusses how it can be applied in capturing the GPS location of pedestrian furniture and facilities. Although some of the spatial data are available from local agencies, still a more detailed data is needed to create a better data model for this study. This study uses a free android application, MAPinr, which is available on the Google PlayStore to collect spatial data on site. It adopted the GNSS and cellular network positioning to locate the position of the required data. As the application allows the captured data to be exported to a GIS platform, the geometric error of the data was improved. In the end, an authenticated spatial dataset comprising pedestrian facilities and furniture in point and line form will be produced and later be used in a pedestrian network analysis study.
\end{abstract}

\section{INTRODUCTION}

Data collection has been considered as the most expensive and time-consuming procedure in a GIS project. It can cost up to $85 \%$ of total cost of a project (Longley, et al., 2011). This is probably due to the high cost of the equipment needed for data capturing as well as the labour cost. The data is also created to serve the purpose of people who need it (Decker, 2001). Most of the time, a GIS project needs a specific data to fit its needs. This has led to primary data capture process instead of relying on other sources. It will probably reduce the cost and will fit the purpose since it is captured by that particular person. However, this will lead to another issue which is time. Data capture can be very time-consuming. For example, collecting the coordinate of a point using GPS surveying method will take at least fifteen minutes to be completed. What if there are hundred points to be captured? It might take days with the conventional survey methods due to the time wasted for setting up the equipment, and transferring to other points. The same procedure will be repeated.

Mobile GIS was later introduced to tackle this issue. It replaces the heavy equipment which needs to be set-up repeatedly with a portable device to capture the data. Formerly, the tablet and personal data assistant (PDA) was used, but these days, mobile GIS are also compatible with smartphones. Hence, capturing data become simpler since everybody carries it in their pocket. It took advantage of the connectivity of the smartphones with data communication as well as the built-in GPS which makes the previous high-cost data capture easier and cheaper. This paper discusses how mobile GIS in an android phone are used in capturing data on field. It focuses on the collection of the footpath furniture and facilities data in supporting an ongoing research study of walkability in Kuala Lumpur central area.

\section{FIELD DATA COLLECTION}

In recent years, the growth of data availability from government agencies and private companies are concurrent with the increasing usage of GIS in many sectors. The publicly available data makes the data acquisition stage easier than before (Chang, 2012; Demers, 2000; Longley, et al., 2011). However, some of GIS project require a more detail and up-to-date data that can be considered confidential by the local agencies. The detailed data are needed for more precise judgement in the GIS analysis. Thus, it is important to search for the available data from the agencies before making decision to create new data. Once it has been confirmed that the data are not available or lacking, then a new data can be created on site.

Positioning is a process of obtaining coordinates by using different observables that act as functions of the coordinates such as distance. Coordinates can be mathematically represented by a scalar number in one, two or three dimensions (Chang, 2011, Dewberry, 2008). The simplest example of a one-dimension coordinate is a distance along a footpath from a certain train station. The two-dimensional coordinates are always described by a set of a planar coordinates such as the horizontal coordinates (northing or easting) in a grid coordinate system or the latitude and longitude of a point on the Earth's surface. On the other hand, the three-dimensional coordinates describe the complete location in space including its height ( $x$, $y, z)$.

\subsection{Conventional Positioning Method}

Before the advancement of mobile GIS, data on field were collected by using ground surveying and GPS surveying. Both methods implement the 3D location principles in obtaining the coordinates of the unknown points with a reference to a known point. The survey will be started at a known point having coordinates such as a boundary marks as a reference to other 
unknown points (Dewberry, 2008). The survey points are relative to one another since they refer to the same reference point. Thus, any measurement errors need to be apportioned between multiple points in a survey. The ground surveying uses the electro-optical devices, such as total stations to measure both angles and distances between two points. GPS surveying on the other hand uses satellites in space to determine the precise locations of the GPS receivers on Earth (Van Sickle, 2008). The receiver measures its distance from satellites by using the travel time and speed of the signals.

Both methods are regarded as the best methods in geospatial study for obtaining highly accurate point locations because the collection of points along a line can create line features and a series of lines can determine an area feature. This will create a vector dataset that will be very useful in any GIS project. However, they are very time-consuming as they need at least two people are needed to carry out the procedure. Even though a single person can handles both, but still it takes time to complete the survey. Not only it is time consuming to set-up the equipment and observing the data, but the post-processing of the data as well requires long time frame. This is why, mobile GIS was introduced to improve the efficiency in GIS data collection procedure.

\subsection{Positioning using Smartphones}

The most innovative GIS development till date is its compatibility with smartphones. Now that all people have one, GIS data collection procedure can be completed easily in a short amount of time with its capability in positioning. What makes smartphones attractive is its compactness. It can easily fit in pocket making data collection procedure no longer a tiring work. It also has considerably large internal storage (up to 64GB) despite its portability (Longley et al., 2011, Weiss, 2002). This is better than conventional GPS equipment which is not only big and heavy, but lack in memory storage.

2.2.1 Global Navigation Satellite Systems (GNSS): This technique is the most commonly used method in mobile positioning, especially for outdoor environments when open views to sky are available. It is a cost-effective method and offers a high accuracy and high availability positions (Chen \& Guinness, 2014, B'Far, 2005). It uses trilateration method using ranging $(\rho)$ observables from the receiver to multiple GNSS satellites as illustrated in Figure 1. The coordinate can be determined in a three-dimensions with three (four for a more precise positioning) ranging variables by using the positions of satellites calculated with the satellite ephemerides obtained from the navigation messages. Since the receiver's clock is not synchronized with GNSS time, it will be added as a parameter in estimating the position $(\mathrm{x}, \mathrm{y}, \mathrm{z}, \Delta \mathrm{t})$.

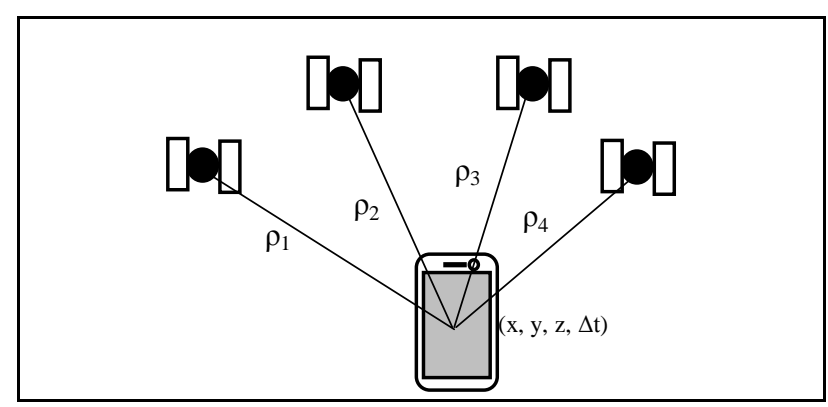

In addition to the stand-alone method, there are three (3) other methods available to enhance the performance of GNSS which are positioning using Assisted GNSS (A-GNSS or A-GPS), Differential GNSS (DGNSS or DGPS) and satellite-based augmentation systems (SBAS). A-GNSS is designed to tackle the delay in the Time-To-First-Fix (TTFF) due to the occurrences of bit errors. Normally, the ephemerides are broadcasted at a rate of 50 bits per seconds making the reception time of a complete navigation dataset be around 18 seconds (Grewal et al., 2007). However, in practice, the reception time can be longer due to the presence of various interruptions to the signals such as urban canyons. The A-GNSS uses assistance from data communication link from cellular networks such as the wireless data connection to speed up the TTFF process.

The second method, DGNSS (or DGPS) is designed to solve the atmospheric errors, satellite and clock errors experienced by the signals when they propagate through atmosphere to ground. It utilises a reference receiver at a known location and a radio broadcast link (Kennedy, 2010). The reference receiver determines pseudorange corrections for spatial and temporal errors which will then broadcasted to the end-user receiver. The positioning accuracy will be improved by applying the corrections to remove errors in the observed pseudoranges. The third method, SBAS operates similarly to the DGNSS. The only differences is that it is a regional system.

2.2.2 Cellular Networks: It is used for positioning in urban areas or indoor environment where the GNSS signals are weak or has severe multipath effects. Radio frequency (RF) signals often adopted for positioning in all environments (Chen \& Guinness, 2014). In smartphones, it is represented in various forms of wireless connectivity including $3 \mathrm{G}, 4 \mathrm{G}$, WLANs and Bluetooth networks. Although these signals were not developed for positioning purposes, since they are correlated spatially it is possible to use them to collect GIS location data.

These RF signals use observables including cell identity of the cellular networks' base stations, the MAC address of access points of short-range RF networks, direction of arrival and more for positioning (Mannings, 2008). As GNSS receiver is now a standard positioning component in most smartphones, A-GNSS can be considered as one of the positioning methods in this category as it requires support from cellular network.

2.2.3 Hybrid method: This method offers a ubiquitous positioning for indoor and outdoor with the combination of GNSS-based and the observables derived from multiple built-in sensors and radio interfaces facilitating wireless data. It combines the GNSS, cellular network positioning techniques for a better accuracy of the data as an addition to various builtin sensors available on the smartphones as shown in Figure 2.

Figure 1. The Concept of GNSS Trilateration 




Figure 2. Hybrid Positioning in Smartphones

Most of the available smartphones on market nowadays operate hybrid positioning with the built-in GNSS and various sensors available on the devices. While built-in GNSS receiver will provide an absolute positioning, other sensors including accelerometers will derive speed, gyroscopes (or digital compass) will show heading change and odometers will measure the travelled distance (Mannings, 2008). This utilisation of the built-in GNSS, various sensors and cellular network (RF) signals in smartphones improves the availability of position fix and simultaneously increase the accuracy of mobile positioning itself.

\section{MOBILE GIS}

Mobile GIS is an extension of the conventional GIS data collection discussed previously. It replaces the time-consuming conventional methods with a more convenient mobile positioning (Singh, 2013). The surveyor can move easily on the field and requires only a portable device to collect the data. Thus, the time taken for a GPS receiver to be set-up on a point will be reduced as the device is now portable. The development of mobile GIS had progressed throughout the years parallel to the growing demand of GIS data collection (Chang, 2012). When the spatial data needs to be collected in a short amount of time, then mobile GIS is one of the solutions. There are several advancements made with the development of mobile GIS including better display and data storage on the local memory of the device that will aid in a better access for the data collected on site.

\subsection{Collecting Points and Lines Dataset using Mobile GIS}

Collecting points and lines dataset using smartphones is very easy with its built-in GNSS and other sensors and connectivity to the RF signals by the cellular network. These properties allow positioning for points and lines indoors and outdoors. The GNSS traces are also very precise. The information recorded can be used to derive parameters such as speed and distance based on time stamps, positions and elevation data logged every second to a file in GPS exchange (GPX) format (Chen \& Guinness, 2014). The GPX is a file format following XML schema that can be used in describing waypoints (points), tracks (lines) and routines. The speed and directions can be calculated by using the time stamp between two consecutive waypoints.

\subsection{Mobile GIS Applications for Tracking and Tracing Available on Market}

There are numerous software and application or tools that can be used for data collection and maintenance available on market. Most of them offers great capabilities in collecting the spatial data and their attributes. One of the most capable software is TerraSync which had been developed by Trimble. It is designed to enhance the efficiency in GIS data collection by using Windows mobile devices (Trimble, 2016). It offers an easy data capture with an optimisation with the integrated digital cameras available on the devices. The data will be collected by using the built-in GNSS receiver on the device in real-time. The attributes data can also be collected using a customisable user-interface to suit the data collection purposes. However, this software can only be operated on Windows-based devices only. Nowadays, most mobile devices, especially smartphones are operated by using Android or iOS. Thus, they need tools that are compatible with their operators to conduct the mobile positioning.

Table 1 shows examples of four mobile GIS that are available for free on market that can be used to collect GPS points by using smartphones. It also supports many sophisticated GIS applications and software. These allow the system to be connected or disconnected to the GIS environment held on the developer server when needed over a wireless connectivity. In general, a smartphone user can navigate by using Google Maps application on his device with the availability of wireless connection. Aside Google Maps, there are many GIS supported applications and software that are available on net either free or paid. They offer different properties from the type of data collected on site to the output data to be used for further analysis.

\begin{tabular}{|c|c|c|c|c|}
\hline Name & MAPInr & \begin{tabular}{|l} 
KML/KMZ Waypoint \\
Reader Free
\end{tabular} & OruxMaps & $\begin{array}{l}\text { Map It - GIS Data } \\
\text { Collector }\end{array}$ \\
\hline Size & $12.48 \mathrm{MB}$ & & $27.88 \mathrm{MB}$ & \\
\hline Developer & $\begin{array}{l}\text { XYLEM Technologies, } \\
\text { Vienna }\end{array}$ & n:n Apps, Texas & Avd. Salmoral, Madrid & $\begin{array}{l}\text { Andrzej Bieniel, } \\
\text { Wishaw }\end{array}$ \\
\hline Basemap & $\begin{array}{l}\text { Google Maps } \\
\text { Google Satellite } \\
\text { Google Hybrid } \\
\text { Openstreetmap } \\
\text { Opentopomap } \\
\text { Mapquest } \\
\text { Opencyclemap } \\
\text { OVI }\end{array}$ & \begin{tabular}{|l} 
Google Maps \\
\end{tabular} & Openstreetmap & $\begin{array}{l}\text { Google Maps } \\
\text { Bing Maps } \\
\text { Openstreetmap } \\
\text { Mapbox }\end{array}$ \\
\hline $\begin{array}{l}\text { Input Data } \\
\text { Type }\end{array}$ & \begin{tabular}{|l} 
Point \\
Line \\
Polygon
\end{tabular} & \begin{tabular}{|l|} 
Point \\
\end{tabular} & $\begin{array}{l}\text { Line } \\
\text { Altitude }\end{array}$ & $\begin{array}{l}\text { Point } \\
\text { Line } \\
\text { Polygon }\end{array}$ \\
\hline $\begin{array}{l}\text { Output Data } \\
\text { Type }\end{array}$ & $\mathrm{km} / \mathrm{kmz} / \mathrm{gpx}$ & $\mathrm{km} / \mathrm{kmz}$ & $\mathrm{km} / \mathrm{kmz} / \mathrm{gpx}$ & $\begin{array}{l}\mathrm{cssi/m} / \mathrm{meeJJSON} / \mathrm{SSO} \\
\mathrm{N} / \mathrm{DXF} / \mathrm{GPX}\end{array}$ \\
\hline $\begin{array}{l}\text { Number of } \\
\text { Downloads }\end{array}$ & $50,000+$ & $10,000+$ & $1,000,000+$ & $50,000+$ \\
\hline $\begin{array}{l}\text { Extra } \\
\text { Features }\end{array}$ & $\begin{array}{l}\text {-Ad-free apps } \\
\text { - Searching function } \\
\text {-Create, load, edit, save } \\
\text { import, export, share } \\
\text { files } \\
\text {-Attaching pictures } \\
\text { - Can open files on } \\
\text { Google Earth } \\
\text { - Can measure distance } \\
\text { and areas } \\
\text { - Can download OSM } \\
\text { for offline usage } \\
\text { - Can work with GPS } \\
\text { deactivated }\end{array}$ & $\begin{array}{l}\text { - Can launched directly } \\
\text { on Google Maps } \\
\text { - Can use for navigation } \\
\text { on Google Maps }\end{array}$ & $\begin{array}{l}\text {-Create, save, share } \\
\text { data } \\
\text {-Download offline } \\
\text { maps } \\
\text {-Attaching pictures, } \\
\text { video to collected data } \\
\text { - Suitable for trekking } \\
\text { activities }\end{array}$ & $\begin{array}{l}\text { - Create, save, edit } \\
\text { - Sharing/export } \\
\text { - Measuring length/area } \\
\text { - GPS satellites status } \\
\text { - Searching function } \\
\text { - Purchasing full } \\
\text { version is needed for } \\
\text { full functionality }\end{array}$ \\
\hline
\end{tabular}

Table 1. Free Mobile GIS Application Available on the Google PlayStore

\subsection{Mobile GIS in Pedestrian-related Studies}

Pedestrian study is probably receiving the most benefits field from the growth of mobile GIS in smartphones. This is due to the fact that people do carry their smartphones to walk and even use it to browse internet when walking. This is very beneficial in limitless pedestrian related study. It is useful in studying the pedestrian travel behaviour, choice of transportation modes and more. As GIS is very capable in developing a database model, it could assists in a better and improved pedestrian study. For 
instance, a pedestrian walkability database were developed in Northern Kentucky to examine the extent and quality of footpath available in one of its district, Campbell County (Hansen, et al., 2009). The application equipped in a PDA and was used for collecting the footpath quality data by using a customised form. The data such as the width and slope of the wheelchair lane are collected to examine the safety of the footpath.

Navigation is another branch of pedestrian study. Giving directions should always be able to satisfy the user needs. Research had shown that landmarks are better in aiding directions for people to reach their destinations (Parush \& Berman, 2004). This made various study involving landmarks for navigation on footpath growing. One example, a GIS data model had been developed with the basis of georeferenced photograph and its attributes such as width, height and more (Gong, et al., 2012). Aside from landmarks, facilities and furniture are also considered as key components in enhancing seamless walking experience for pedestrian (Transport for London, 2005; Zakaria \& Ujang, 2014; Cambra, 2012; Department of Transport, 2007; ITE Technical Council Committee 5A-5, 1994). A well-equipped footpath with furniture such as benches and shelters will make the walking more pleasant. The following section discusses the methodology of collecting the pedestrian furniture and facilities data on site by using mobile GIS.

\section{CAPTURING GPS LOCATIONS FOR PEDESTRIAN FURNITURE AND FACILITIES USING MAPInr FOR ANDROID}

The study was conducted at the central area of Kuala Lumpur. The GPS positions of all facilities and furniture associated to the footpath were captured by using MAPInr application. The procedure of capturing the data began with planning stage where the data required for the study was listed. In the preparation stage, the best-suited GIS data collection android application available was selected from the four shortlisted as described in Table 1. Subsequently, the form for attribute data entry was designed. Once the preparation is completed, the process of capturing the data on field was carried out. Upon returning from site, the accuracy of the data was validated. The detailed procedure will be described in the next section.

\subsection{LISTING AND CAPTURING THE PEDESTRIAN FACILITIES AND FURNITURE DATA}

Preparation is a very important step in data collection procedure of any GIS project. It will affect the smoothness of data capturing process on the field. A good preparation can minimise any circumstances on site especially software-related errors such as errors in entering attributes of the data or slow or freezing software while collecting data on site. The first step is listing the data required for the study. It is important to know the type of the data required either in point, line or polygon form.

In this study, there are seven (7) data that was captured on site. The reason for the capture is that some of the data is confidential and therefore could not be distributed to public. In addition, some of the data that is available at the local agencies lacks of detail for this study. Thus, a more detailed data are needed for a better data model. Table 2 shows the type of data to be captured on site.

\begin{tabular}{|c|c|}
\hline Category & Type of Data \\
\hline \begin{tabular}{ll}
\multicolumn{2}{l}{ Signage } \\
- & showing name \\
- & showing distance \\
- & showing direction \\
\end{tabular} & \multirow{5}{*}{ Point } \\
\hline Resting points & \\
\hline Food and Beverages Vendor & \\
\hline Traffic lights & \\
\hline Crossings & \\
\hline \begin{tabular}{ll}
\multicolumn{2}{l}{ Shelter (row of) } \\
$-\quad$ & Roof \\
- & Trees
\end{tabular} & \multirow{2}{*}{ Line } \\
\hline \begin{tabular}{ll}
\multicolumn{2}{l}{ Separator from vehicle road (row of) } \\
$-\quad$ & Hand-rail \\
- & Trees \\
\end{tabular} & \\
\hline
\end{tabular}

Table 2. List of data captured on site

In this study, the roof and trees data will be captured as a line instead of polygons or points. This is because, the study aims to determine the type of pedestrian facilities or furniture available on the footpath network instead of the width attribute of the roof and the coordinate for each of the trees.

\subsubsection{Selecting the Android Application for Data Capture}

Since there are various GIS data capturing applications available on the market, it is vital to choose the best suited for the study's aim and purposes. For this study, the application must fulfil four key considerations to ensure the data capturing process run smoothly. First, the application should be supported by the android devices to be used in collecting the spatial data. Second, it should be able to capture all types of data required. Third, it should allow the file to be created, save and edited. Lastly, it should allow the data to be exported to GIS environment. Based on the key considerations, MAPinr was selected as it supports the 5.0-inch Sony Xperia M5 smartphone operated on Android version 5.1 used in this study. It can also capture point and line data needed and save data captured on file created locally or on the cloud. The file can be re-opened for editing or continuing the previous works. It allows the captured data to be later exported to GIS platform such as ArcGIS for further analysis. The data are saved as $\mathrm{kml}$ that can later be converted into shapefile (.shp) to be used in ArcGIS environment. These functionality proved that MAPinr is a very user-friendly application and fit the purpose of this study.

\subsubsection{Preparing the Attribute Data Form Entry:}

Apart from the spatial data, attribute data is also important in GIS project. The data should not only contain the coordinate of a point, but must have its attribute that describe the data. In this study, the key attribute is the data category (or its subcategory). To differentiate the data accordingly to their respective category, the attribute data entry form is presented as in Figure 3. 

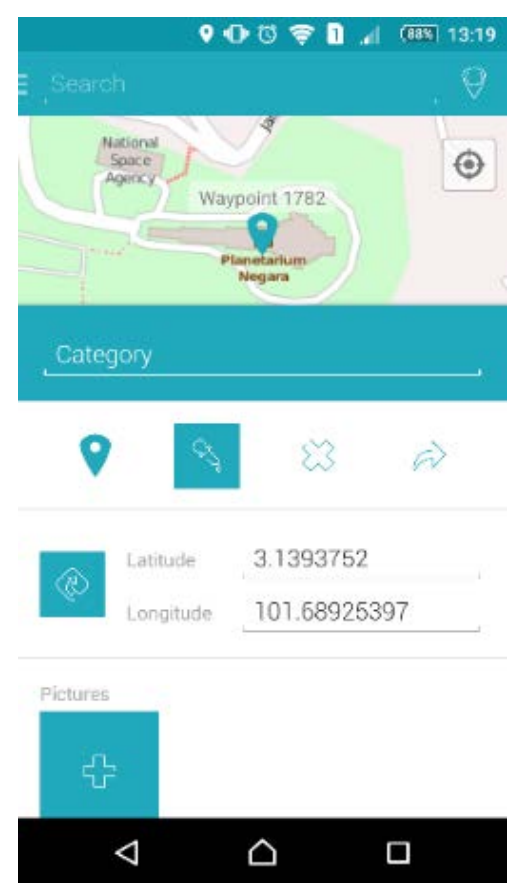

Figure 3. Attribute Data Entry Form as Provided by MAPinr

\subsection{CAPTURING DATA ON SITE}

The process of collecting the GPS data on site using mobile GIS method is relatively simple when it no longer involves the conventional GPS receiver. Instead, it uses a compact smartphone equipped with selected GIS data collection application. Once the preparation is completed, MAPinr application was installed in the Sony Xperia M5 equipped with the built-in A-GNSS and other sensors including accelerometer, proximity and compass. The built-in multisensors in the smartphone and the connection to 4G LTE network, had aided the mobile positioning in capturing the GPS location of points and lines needed in this study. The number of collected data on site is described in Table 3.

While walking along the footpath as mapped by the local authority (Kuala Lumpur City Hall), the data will be captured. Their category will be recorded in the attribute-entry form as shown in Figure 4. In total, 1778 data was collected on site in 13 days.

\begin{tabular}{|c|l|l|c|}
\hline $\begin{array}{c}\text { Type of } \\
\text { Data }\end{array}$ & \multicolumn{1}{|c|}{ Category } & \multicolumn{1}{|c|}{ Subcategory } & $\begin{array}{c}\text { Data } \\
\text { Count }\end{array}$ \\
\hline \multirow{4}{*}{ Point } & \multirow{4}{*}{ Signage } & Showing name & 576 \\
\cline { 3 - 4 } & & Showing distance & 10 \\
\cline { 2 - 4 } & & Showing direction & 113 \\
\cline { 2 - 4 } & Resting points & 254 \\
\cline { 2 - 4 } & Food and Beverages Vendor & 225 \\
\cline { 2 - 4 } & Traffic lights & 106 \\
\cline { 2 - 4 } & Crossings & 136 \\
\hline \multirow{4}{*}{ Line } & Shelter & Roof & 34 \\
\cline { 2 - 4 } & Separator from & Trees & 165 \\
\cline { 2 - 4 } & vehicle road & Trees & 130 \\
\hline \multicolumn{2}{|c|}{ Total } & $\mathbf{1 7 8 8}$ \\
\hline
\end{tabular}

Table 3. Data Count Collected on Site according to their Name

\subsection{Data Post-Processing}

The quality of the collected data must be improved for further GIS analysis. The post-processing procedure commenced when the data is transferred to the ArcGIS environment. Subsequently, the data will be classified according to their type and the quality of data will be improved by repairing the geometric error of the data to enhance a better analysis.

\subsubsection{Data Transfer to ArcGIS Environment}

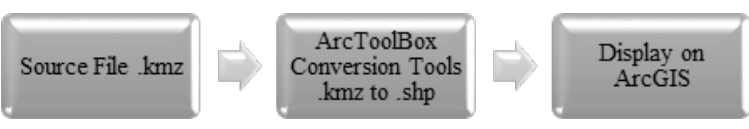

Figure 4. Process of Translating Source File to ArcGIS compatible Shapefile

The data collected by MAPinr apps is initially stored in the smartphone's local memory and will be exported to ArcGIS as illustrated in Figure 4. This was accomplished by connecting the smartphone to desktop system and opening the data in ArcGIS workspace. MAPinr offers the captured data to be stored in various formats including $\mathrm{kml}, \mathrm{kmz}$ and GPX. These formats are compatible with other web-mapping services including Google Earth or converted to be used in ArcGIS environment.

In this study, the collected data was stored in kmz format. This data will be converted into shapefile using Conversion Tools in ArcToolbox. Then, the data are reclassified according to its type (point, line dataset). This process will clean-up the data as they have different relationship with the footpath network that will be discussed in the next section. Figure 5 shows the raw dataset collected that had been imported into ArcGIS environment.

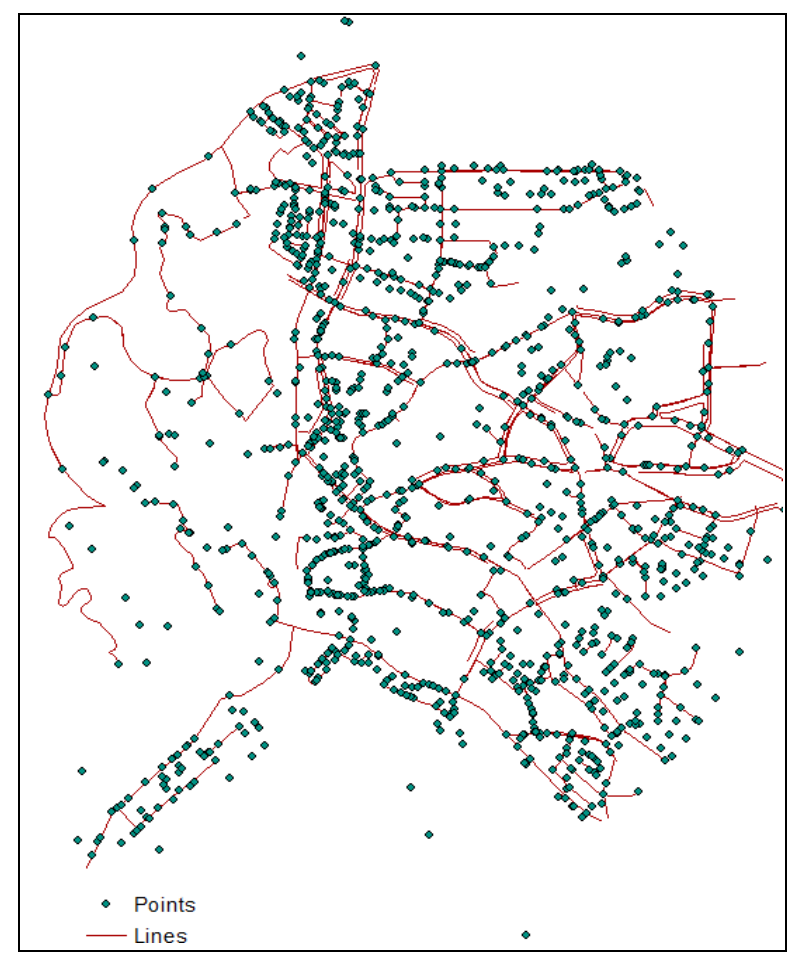

Figure 5. Raw Point and Line Dataset Collected on Site 


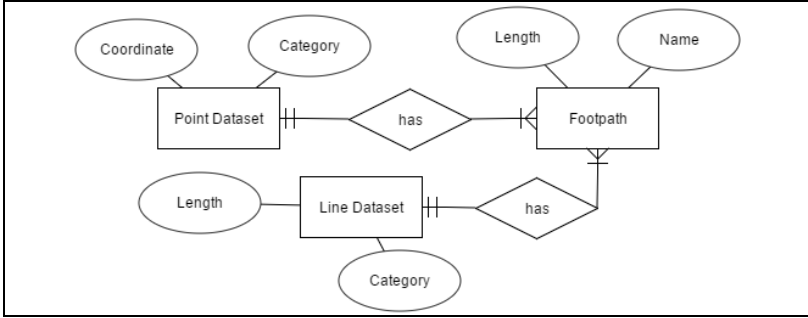

Figure 6. Data Model of Collected Datasets and Footpath

Data editing and improvement are intended to correct any geometric error of the data captured on site. The process is done by checking any topological error of the data with the help of topological rules as described in Table 4. The rules are associated to the relation in the data model as illustrated in Figure 6. All the data are related to the footpath dataset. This is to ensure the further network analysis of the footpath dataset is as precise as possible. The topological error for each data will be fixed and validated. Finally, the clean-up data is now ready to be used for further analysis as displayed in Figure 7.

\begin{tabular}{|l|l|l|}
\hline $\begin{array}{l}\text { Type of } \\
\text { Data }\end{array}$ & Topological Rules & Explanation \\
\hline Point & $\begin{array}{l}\text { Must be covered by } \\
\text { line }\end{array}$ & $\begin{array}{l}\text { All points must be on the } \\
\text { footpath network }\end{array}$ \\
\hline \multirow{2}{*}{ Line } & Must not have dangles & $\begin{array}{l}\text { Line should intersect with } \\
\text { each other }\end{array}$ \\
\cline { 2 - 3 } & $\begin{array}{l}\text { Must be covered by } \\
\text { feature class of }\end{array}$ & $\begin{array}{l}\text { Line must be covered with } \\
\text { the footpath network }\end{array}$ \\
\hline
\end{tabular}

Table 4. Topological Rules for Checking the Topological Error of the Data (ESRI, 2014)

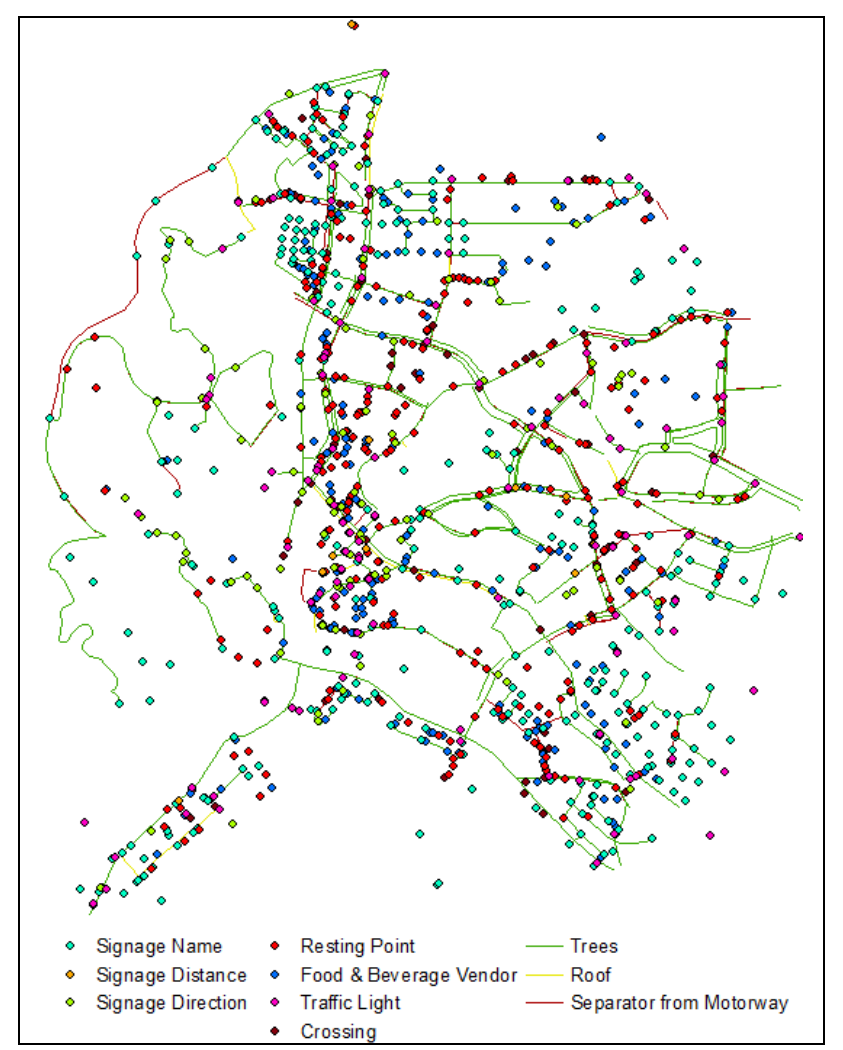

\section{CONCLUSION}

Collecting data can be a very laborious in a GIS project. It requires a lot of time, high costs and others. Nevertheless, the mobile GIS can simplify the process apart from its compatibility with smartphones. With the abundance of applications developed to support the GIS data collection available on the net, mobile GIS has been the major focus. The ongoing research and development in creating better application that suit many purposes will make mobile GIS a better technology in the future. However, one set back of this method is the accuracy. While data capturing can be very simple, the geometric quality of the data needs to be improved by fixing their topological errors. Although some application claims they acquire the coordinates accurately, the presence of noise error in the signals will reduce the positioning accuracy. This is one probable reason why some projects still need the conventional field surveying method since it delivers the best quality of the data. It is hoped in the future that a better GPS-enabled smartphones will be developed to improve the quality of the data.

\section{REFERENCES}

B'Far, R., 2005. Mobile Computing Principles: Designing and Developing Mobile Applications with UML and XML. 1st ed. Cambridge: Cambridge University Press.

Cambra, P., 2012. Pedestrian Accessibility and Attractiveness Indicators for Walkability Assessment, Lisbon: Department of Civil Engineering and Architecture, Instituto Superior Técnico, Universidade Técnica de Lisboa.

Chang, K.-t., 2012. Introduction to Geographical Information Systems. 6th ed. New York: McGraw Hill.

Chen, R. \& Guinness, R. E., 2014. Geospatial Computing in Mobile Devices. 1st ed. Norwood: Artech House.

Decker, D., 2001. GIS Data Sources. 1st ed. New York: John Wiley \& Sons.

Demers, M. N., 2000. Fundamentals of Geographic Information Systems. 2nd ed. New York: John Wiley \& Sons.

Department of Transport, 2007. Manual for Streets. 1st ed. London: Thomas Telford.

Dewberry, S. O., 2008. The Land Development Handbook: Planning, Engineering and Surveying. 3rd ed. New York: McGraw-Hill.

ESRI, 2014. ArcGIS Desktop: Release 10.3. Redlands, California: Environmental Systems Research Institute.

Gong, H., Chen, C., Bialostozky, E. \& Lawson, C. T., 2012. A GPS/GIS method for travel mode detection in New York City. Computers, Environment and Urban Systems, Volume 36, pp. 131-139.

Grewal, M. S., Weill, L. R. \& Andrews, A. P., 2007. Global Positioning Systems, Inertial Navigation, and Integration. 2nd ed. New Jersey: John Wiley \& Sons, Inc.

Hansen, W. et al., 2009. Development of a Pedestrian Walkability Database of Northern Kentucky Using Geographic Information System (GIS). Journal of Physical Activity and Health, Volume 6, pp. 374-385.

Figure 7. Topological Edited Data and their Types 
ITE Technical Council Committee 5A-5, 1994. Design and Safety of Pedestrian Facilities, Washington DC: Institute of Transportation Engineers.

Kennedy, M., 2010. The Global Positioning System and ArcGIS. 3rd ed. Boca Raton: CRC Press Taylor \& Francis Group.

Longley, P. A., Goodchild, M. F., Maguire, D. J. \& Rhind, D. W., 2011. Geographic Information Systems \& Science. 3rd ed. Danvers: John Wiley \& Sons. Inc.

Mannings, R., 2008. Ubiquitous Positioning. Norwood: Artech House, Inc.

Parush, A. \& Berman, D., 2004. Navigation and orientation in 3D user interfaces: the impact of navigation aids and landmarks. International Journal of Human-Computer Studies, 61(3), p. 375-395.

Singh, H., 2013. Mobile Data Collection Using an Android Device. International Journal of Computer Science and Technology, 4(1), pp. 200-202.

Transport for London, 2005. Transport for London - Improving Walkability, London: Mayor of London.

Trimble, 2016. TerraSync Software. Sunnyvale, California: Trimble Navigation Limited.

Van Sickle, J., 2008. GPS for land surveyors. 3rd ed. Boca Raton: CRC Press.

Weiss, S., 2002. Handheld Usability. West Sussex: John Wiley \& Sons Ltd.

Zakaria, J. \& Ujang, N., 2014. Comfort of Walking in the City Centre of Kuala Lumpur. Seoul, Asian Conference on Environment-Behaviour Studies. 